\title{
Estudo sobre "Quantidade de substância" e Mole
}

\author{
ANA F. P. ABRANTES*, CATARINA S. G. VIEIRA* E M. FERNANDA P. SILVA**
}

\begin{abstract}
Resumo
Neste trabalho procurou averiguar-se que conhecimento possuem professores profissionalizados com vários anos de experiência, professores em profissionalização (estágio integrado no último ano da licenciatura) e alunos do $1 .^{\circ}$ ano da universidade, acerca de "quantidade de substância" e de mole. Aplicou-se um inquérito com perguntas e questões para comentar.
\end{abstract}

Verificou-se identificação da grandeza "quantidade de substância" com a sua unidade, mole, identificação quer de mole, quer de "quantidade de substância", com massa, número de moles, número de partículas e constante de Avogadro, falta de conhecimento sobre a origem e evolução histórica dos conceitos e não identificação da definição de mole.

\section{Introdução}

O conceito de mole tem sido objecto de investigação nas últimas décadas em diferentes paises. A maioria dos aspectos investigados referem-se a dificuldades de aprendizagem, dificuldades de ensino, pré-requisitos necessários para a aprendizagem, origem e evolução histórica do conceito, análise do conceito em livros de texto, etc. Estudos envolvendo, além da mole, também o conceito de "quantidade de substância", referem quer dificuldades de aprendizagem dos alunos, quer conhecimentos dos professores sobre os conceitos em si (1).

Dos trabalhos publicados com dificuldades de aprendizagem referem-se alguns: sobre cálculos estequiométricos com métodos algorítmicos envolvendo a mole (2-4) e a "quantidade de substância" (5-7); sobre identificação de mole com massa e número de partículas ou considerando a mole como uma propriedade de uma molécula (8-10); sobre concepções erradas dos alunos em que a "quantidade de substância" se confunde com massa de reagente ou com massa molar de reagente (10) ou com concentração(6); sobre concepções dos alunos àcerca do significado de "1 mol"(11), etc.. Dos trabalhos publicados com estudos efectuados com professores pode referir-se os relativos a diferentes concepções qualitativas que os mesmos têm àcerca de mole e ao modo como introduzem a noção (como um número ou como massa, para posteriormente formalizarem relações matemáticas) (11-13), desconhecimento sobre a origem e evolução sofrida pelos conceitos "quantidade de substância" e mole (14), etc..

Os resultados foram obtidos, no geral, com uma população diversificada de professores (efectivos, estagiários e universitários) e alunos desde o ensino secundário ao universitário (16-19 anos).

Em Portugal só se conhece um estudo acerca das dificuldades de aprendizagem do conceito de mole, efectuado com professores (15). O presente estudo foi efectuado com alunos do $1 .^{\circ}$ ano da Universidade de Aveiro (U.A.) inscritos na disciplina de Química (2. ${ }^{\circ}$ semes- tre); professores do estágio integrado da Licenciatura em Ensino da Física e da Química daquela Universidade e professores efectivos de escolas de Aveiro e de Coimbra, no ano lectivo 2001/2002; tem como objectivos averiguar quais as ideias que professores profissionalizados com vários anos de experiência e professores em profissionalização (alunos do último ano da licenciatura em ensino da Física e da Química) e alunos do $1 .^{\circ}$ ano da U.A. possuem acerca dos conceitos em questão, e fazer a comparação entre os resultados de cada grupo de inquiridos.

\section{Parte experimental}

\subsection{Questionário e amostras usadas}

O trabalho experimental foi efectuado através da aplicação de um questionário. Da população alvo constam três grupos distintos: os alunos do $1 .^{\circ}$ ano de quatro turmas práticas da disciplina de Química, leccionada no $2 .^{\circ}$ semestre do ano lectivo de 2001/02, na Universidade de Aveiro, em número de $55(\mathrm{~N}=55)$; 
professores estagiários do núcleo de estágio integrado da licenciatura em Ensino de Física e Química daquela Universidade, no mesmo ano lectivo, em número de 18 ( $\mathrm{N}=18)$; e professores com experiência de escolas de Aveiro e Coimbra em número de $29(\mathrm{~N}=29)$.

0 questionário era composto de onze questões para os professores e sete para os alunos, sendo estas comuns às dos professores. Destas sete questões comuns uma era uma pergunta acerca de "quantidade de substância", e as outras seis eram frases para comentar. Estas frases continham todas a palavra mole, uma delas correctamente e as outras cinco num contexto errado. As frases incorrectas foram retiradas de dois livros de texto aconselhados para o ensino secundário (16-17) e de um para o ensino superior (18), reconhecido internacionalmente. Das outras quatro questões dos professores uma era acerca da origem e evolução do conceito de mole, e as outras três estavam directamente relacionadas com a experiência profissional do professor.

Pediu-se que as respostas fossem dadas individualmente, após o acto da leitura, sem recurso a qualquer tipo de consulta. Os alunos deram as respostas nos últimos dez minutos de uma aula prática de duas horas.

Com as diferentes questões do inquérito, pretendia-se, de entre outros objectivos, verificar se os inquiridos sabem qual a origem e evolução histórica dos conceitos de "quantidade de substância" e de mole, que a mole é a unidade da grandeza "quantidade de substân- cia" e que não deve ser confundida com a própria grandeza, que nem a "quantidade de substância" nem a mole devem ser consideradas como número de quaisquer partículas ou como massa (embora entre massa e "quantidade de substância" haja uma relação de proporcionalidade (19)).

\section{2 - Resultados e sua análise}

Os resultados obtidos são apresentados em paralelo para os três grupos de inquiridos.

Na tabela 1 encontram-se os resultados obtidos com a questão 1 :

Questão1.Em Ciência cada grandeza tem definida a sua unidade, mediante uma convenção e aceitação universal. Considere a grandeza quantidade de substância. Qual o significado físico desta grandeza? (14)

Como se pode observar pela tabela 1 a mais elevada percentagem de respostas dos professores $(44,8 \%)$ e dos estagiários $(33,3 \%)$ inquiridos diz respeito à identificação da grandeza "quantidade de substância" com número de partículas, enquanto que nos alunos a maior percentagem se refere a "número de moles"; os professores e os estagiários identificam o significado físico de "quantidade de substância" com a sua unidade, mole, e apenas 6,9\% dos professores e $16,7 \%$ dos estagiários conhecem o significado físico da grandeza (resposta correcta). A confusão de "quantidade de substância" com massa (3,6\%) e com a constante de Avogadro (5,5\%) verifica-se apenas nos alunos. As respostas classificadas como incoerentes são respostas que não têm nada a ver com o que se pergunta.

Das várias perguntas em que o objectivo era verificar a identificação de mole com número de partículas apresentam--se os resultados de duas, questões 6 e 7 .

Na tabela 2 apresentam-se os resultados referentes à questão 7:

Qestão 7 - Comente a seguinte frase: " $A$ mole é uma medida de quantidade de substância, expressa por um número, $6 \times 10^{23}$, tal como outras unidades de medida: a dezena, a dúzia, o quarteirão, etc..." (17)

Da análise da tabela 2 verifica-se que há confusão de mole com constante de Avogadro por parte dos três grupos de inquiridos; os professores são os que o fazem em maior percentagem, 58,6\%, seguindo-se os estagiários com sensivelmente metade, $27,8 \%$. As respostas correctamente dadas verificam-se em maior percentagem nos estagiários, $33,3 \%$.

Com a questão 6:

Comente a frase: "1 mole (1 mol) é o número de átomos em exactamente $12 \mathrm{~g}$ de carbono-12" (18),

verificou-se identificação de 1 mole com número de partículas pela maioria dos professores $(34,5 \%)$ e estagiários (38,9\%), apresentando ambos percentagens idênticas de respostas incoerentes $(\sim 34 \%)$; os alunos fazem a identificação de mole com massa em maior percentagem (29,1\%), mas $32,7 \%$ não sabem ou não respondem.

\section{Tabela 1 - Identificação da grandeza "quantidade de substância" com mole, n. ${ }^{\circ}$ moles, massa, n. ${ }^{\circ}$ partículas, em \%}

\begin{tabular}{llllllll}
\hline Grupo & Mole & $\begin{array}{l}\text { N. }{ }^{\circ} \\
\text { de Moles }\end{array}$ & Massa & $\begin{array}{l}\text { N. }{ }^{\circ} \\
\text { de Partículas }\end{array}$ & $\begin{array}{l}\text { Constante } \\
\text { de Avogadro }\end{array}$ & $\begin{array}{l}\text { Resposta } \\
\text { Correcta }\end{array}$ & $\begin{array}{l}\text { Resposta } \\
\text { Incoerente }\end{array}$ Não sabe \\
Não responde
\end{tabular}


Tabela 2 - Identificação da unidade mole com constante de Avogadro, em \%

\begin{tabular}{|c|c|c|c|c|c|}
\hline Grupo & $\begin{array}{l}\text { N. }{ }^{\circ} \text { de } \\
\text { Partículas }\end{array}$ & $\begin{array}{l}\text { Constante } \\
\text { de Avogadro }\end{array}$ & $\begin{array}{l}\text { Resposta } \\
\text { Correcta }\end{array}$ & $\begin{array}{l}\text { Resposta } \\
\text { Incoerente }\end{array}$ & $\begin{array}{l}\text { Não sabe / } \\
\text { / Não responde }\end{array}$ \\
\hline Prof.s & & 58,6 & 17,2 & 24,1 & \\
\hline Estag.s & & 27,8 & 33,3 & 5,6 & 33,4 \\
\hline Alunos & 3,6 & 18,2 & 14,6 & 32,7 & 30,9 \\
\hline
\end{tabular}

Tabela 3 - Identificação da definição de mole segundo a IUPAC

\begin{tabular}{|c|c|c|c|c|c|}
\hline Grupo & Massa & N. ${ }^{\circ}$ de Partículas & Resposta Correcta & Resposta Incoerente & Não sabe / Não responde \\
\hline Prof.s & & & 17,2 & 20,7 & 62,1 \\
\hline Estag.s & & & 27,8 & & 72,2 \\
\hline Alunos & 9,1 & 1,8 & 12,7 & 9,1 & 67,3 \\
\hline
\end{tabular}

Uma das questões do inquérito dizia respeito à definição da unidade mole. A definição foi proposta em 1961 pela União Internacional de Física Pura e Aplicada, adoptada em 1965 pela União Internacional de Química Pura e Aplicada e estabelecida em 1971 pela $14 .^{\text {a }}$ Conferência Geral de Pesos e Medidas (CGPM); tem a redacção apresentada na questão 11 :

Questão 11. Comente a seguinte frase: "A mole é a quantidade de substância de um sistema que contém tantas entidades elementares quantos os átomos que existem em 0,012 kg de carbono$12^{\prime \prime}(20)$

Os resultados obtidos com esta questão encontram-se na tabela 3.

Pode observar-se que a maior percentagem das respostas dadas pelos elementos dos três grupos de inquiridos, correspondem ao não reconhecimento da definição de mole (não sabe / não responde) segundo as indicações da $14{ }^{\text {a }}$ CGPM. Dos professores 17,2\% conhecem a definição correcta e dos professores em estágio são $27,8 \%$ os que sabem a definição correcta.

0 resultado da questão 5, posta a professores e a estagiários:

Questão 5. Tem alguma informação sobre a origem histórica e sobre a evolução histórica do conceito de mole? Se sim, comente-a (14),

mostrou que apenas 3,4\% dos professores tinha conhecimento fazendo referência aos trabalhos realizados pelo professor espanhol Rafael Azcona; dos estagiários verificou-se não possuirem informação significativa; destes quem apresentou alguma informação apenas refere que o conceito teve origem em experiências feitas por Avogadro sobre gases.
Das três questões directamente relacionadas com a experiência profissional dos professores a pergunta 4 era:

Que aspectos o professor deve ter em consideração na introdução do conceito de mole na aula?" (14);

o resultado do inquérito revela que a maioria dos professores acha que se deve relacionar a mole com outras unidades de medida do conhecimento dos alunos, que se deve fazer comparação com a dúzia, dezena, etc (evidenciando a confusão entre a unidade e o número de partículas) embora outros achem que se deve fazer bem a distinção entre a grandeza "quantidade de substância" e a sua unidade (opinião partilhada também por estagiários), realçando a diferença com massa, volume e número de partículas. Alguns estagiários dizem que se deve dar atenção às concepções alternativas, e outros dizem que o profes- 
sor deve estar bem familiarizado com o conceito e ter as ideias bem claras e estruturadas para o conseguir transmitir de forma correcta.

A pergunta 2 referia-se à idade do aluno mais adequada para a introdução do conceito "quantidade de substância", se no $8 .^{\circ}$ ou no $10{ }^{\circ}$ ano de escolaridade: a maioria, quer dos professores, quer dos estagiários, é de opinião que deve ser no $10^{\circ}$ ano, apontando como razão principal o facto de o conceito ser abstracto e de difícil compreensão; os que não concordam acham que deve ser o mais cedo possivel para que o mesmo se vá interiorizando gradualmente.

Sobre a pergunta 3 , acerca do modo como o conceito é abordado nos manuais escolares, a opinião geral dos estagiários que se pronunciaram é que o conceito é abordado de forma pouco precisa e com poucos exemplos, podendo reforçar as concepções alternativas dos alunos; dos professores há quem tenha a mesma opinião, mas há quem considere que alguns livros apresentam abordagens correctas.

A análise das frases retiradas dos manuais escolares utilizados neste trabalho e incluidas no questionário mostram que há falta de rigor na definição de mole e no significado de "quantidade de substância". Num dos livros, "1 mole" é o "número de átomos..." (18); em outro livro aparecem duas definições diferentes de mole, uma em que esta unidade é identificada como "uma medida de quantidade de substância, expressa por um número...", e a outra em que a mole é identificada como a "quantidade de substância que contém tantas partículas...", e ainda, noutra frase, faz-se a identificação de "quantidade de substância" com "número de moles", "número real de partículas" e "massa" (17); no outro livro utilizado neste trabalho aparece a definição de "concentração de uma substância numa solução" como sendo "número de moles de substância ..."(16).

\section{3 - Conclusões}

O domínio dos conceitos que se pretendem ensinar, isto é, a familiarização com os conceitos e a clareza e estruturação das ideias por parte de quem lecciona é muito importante para a correcta transmissão de conhecimentos.

Verificou-se, pelos resultados obtidos, que de entre os professores há quem não tenha as ideias bem esclarecidas, fazendo a identificação de mole com número de moles e com constante de Avogadro, desconhecendo a definição de mole segundo a 14. a CGPM (alguns considerando que a definição é "inadequada, confusa, errada,..."), desconhecendo o significado físico da grandeza "quantidade de substância" (já que a identificam com números de partículas e de moles). Não se observou nos professores conhecimento acerca da origem e evolução do conceito de mole.

Os resultados dos professores estagiários são mais positivos que os dos professores, nalguns aspectos, por exemplo, no significado físico de "quantidade de substância", mas na definição correcta de mole segundo a $14 .{ }^{\text {a }}$ CGPM estão equiparados. Os resultados dos estagiários também são, de uma forma geral, mais positivos que os dos alunos, o que leva a concluir que houve evolução dos conceitos com o aumento de formação científica.

$\mathrm{O}$ facto de os alunos não terem conhecimento do significado físico de "quantidade de substância", pode ser resultante do facto de professores e estagiários utilizarem, na sua maioria, a expressão "número de moles" para designar aquela grandeza.

É de notar o facto de grande percentagem de respostas dadas por professores e por estagiários, serem desajustadas às perguntas feitas, facto que revela pouco esclarecimento e falta de familiarização com os conceitos.

Nos livros de texto consultados observou-se alguma falta de rigor na terminologia científica utilizada para os conceitos em questão,

\section{Bibliografia:}

1 C. Furió, R. Azcona e J. Guisola, Enseñanza da Las Ciencias, 20(2) (2002) 229
2 J. N. Lazonby, J. E. Morris e D.J. Waddington, Journal of Chemical Education, 62(1) (1985) 60

3 J. R. Staver e A. T. Lumpe, Journal of Research in Science Teaching, 32(2) (1995) 177

4 D. Gabel e R. D. Sherwood, Journal of Research in Science Teaching, 21(8) (1984) 843

5 M. J. Frazer e D. Servant, Education in Chemistry, 23(2) (1986) 54

6 A. Vincent, Education in Chemistry, 18(4) (1981) 114

7-H.-J. Schmidt, International Journal of Science Education, 16(2) (1994) 191

8 S. Novick e J. Menis, Journal of Chemical Education, 53(11) (1976) 720

9 R. Cervellati, A. Montuschi, D. Perugini, N. Grimellini-Tomasini e B. Pecori Balandi, Journal of Chemical Education, 59(10) (1982) 852

10 H.-J. Schmidt, International Journal of Science Education, 12(4) (1990) 457

11 A. Tullberg, H. Stromdahl e L. Lybeck, International Journal of Science Education, 16(2) (1994) 145

$12 \mathrm{H}$. Stromdahl, A. Tullberg e L. Lybeck, International Journal of Science Education, 16(1) (1994) 17

13 P. G. Nelson, Education in Chemistry, 28(4) (1991) 103

14 C. Furió, R. Azcona e J. Guisola, Enseñanza da Las Ciencias, 17(3) (1999) 359

15 M. E. Elias e A. Elias, Boletim da Sociedade Portuguesa de Química, 12 (1982) 8

16 S. Formosinho, V. Gil, J. Dias e A. Cardoso, Química para $\pi$, 8. ${ }^{\circ}$ ano, 2. ${ }^{\text {a }}$ edição. Coimbra: Livraria Minerva, 1987

17 L. Mendonça e M. Ramalho, No mundo em transformaçăo, Quimica- $8 .^{\circ}$ ano. Lisboa: Texto Editora, 1991

18 L. Jones e P. Atkins, Chemistry: Molecules, Matter and Change, $4 .^{a}$ ed., Freeman: New York, 2000, p.64

19 M. E. Jardim e M. P. Pereira, Terminologia, Simbolos e Unidades para Grandezas Fisico-Químicas, Lisboa: Escolar Editora, 1985, p. 19

20 I. M. Mills, T. Cvitas, K. Homann, N. Kallay e K. Kuchitsu, Quantities, units and symbols in physical chemistry, Oxford: Blackwell, 1988, p.64 